\title{
Perioperative and anesthetic deaths: toxicological and medico legal aspects
}

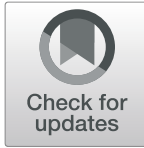

\author{
Antonina Argo ${ }^{1 *}$, Stefania Zerbo ${ }^{1}$, Antonietta Lanzarone ${ }^{1}$, Roberto Buscemi ${ }^{1}$, Roberta Roccuzzo ${ }^{1}$ and \\ Steven B. Karch ${ }^{2}$
}

\begin{abstract}
Background: Anesthesia has become safer during decades, though there is still a preventable mortality; the complexity of medical and surgical interventions, increasingly older and sicker patients, has created a host of new hazards in anesthesiology. In this paper, some of these perioperative (PO) fatal adverse events are investigated in terms of health responsibility. Selective literature research in several data bases, concerning perioperative and anesthetic deaths and medical responsibility, was performed.

Main text: A generally accepted definition of the anesthesia and perioperatory-related death still remains one of the major concerns in forensic pathology, and the terms "operative deaths" and "anesthetic deaths" are usually applied inaccurately within the medico-legal literature. Such events involve comprehensively PO fatalities and allow for subtle separation of natural and unnatural death, at least from the prospective of forensic pathology. latrogenic deaths in this field can be separated into some major categories, as attributable to previous patient's unfavorable conditions or depending from surgical procedure per se (such as PO cardiac and cerebrovascular events). In this review, the authors carried out syntheses of specific research areas regarding epidemiology, complications of general and spinal anesthetic, failure in airway management and patient's circulatory homeostasis, and adverse drugs reactions; analysis considering the challenge of anesthetic-related mortality, epidemiology and classifications, by indicating causal chain of death, in respect of both contributing and associated anesthetic and surgery facts.
\end{abstract}

Conclusions: Perioperative quality control programs and its relevance for medico-legal evaluation are emphasized as, although mortality rates have decreased worldwide over the last decades, however, preventable drug-related deaths still happen. Such fatal events have to be considered within the field of forensic pathology experts, with regard of malpractice claims, to implement a strategy for preventing potentially fatal complications.

Keywords: Anesthesia, Causal chain, Drugs, Epidemiology, Errors, Fatalities, Medico-legal, Responsibility, Surgery

\section{Background}

It is believed that the first case of death related to anesthesia happened in 1847, as a consequence of pulmonary unrecognized pulmonary disease caused by the administration ("ab ingestiis") of brandy administered to counter the effects of inhaled chloroform (Vassalo 1997). From the beginning of anesthetic practice, concerns were expressed that inhaled gasses might cause brain hypoxia, despite medical usefulness. From evidence, anesthesia has become safer over the decades (Gaba 2000), and anesthetic and PO mortality rates have decreased worldwide over the last

\footnotetext{
* Correspondence: antonella.argo@libero.it

${ }^{1}$ Department Pro.Mi.Se, Legal Medicine, School of Medicine, University of

Palermo, Via del Vespro 129, 90127 Palermo, Italy

Full list of author information is available at the end of the article
}

decades. However, as the developments of the surgery allow to treat patients with multiple diseases in the extreme ages of life (Gaba 2000), the surgical and anesthetic risks increase (Lagasse 2002). There have been significant efforts to analyze errors and investigate critical incidents, and these are recently discussed in the Helsinki declaration on patient safety in anesthesiology (Mellin-Olsen et al. 2010). The decreasing mortality rate depends on adopted safety measures, for example improved monitoring actions and the systematic use of risk prevention guidelines (Cooper et al. 1984). However, preventable drug-related deaths remain (Bainbridge et al. 2012); though, the goal of "zero anesthesia-related deaths" (Macintosh 1948) is still far from being achieved as the epidemiology of PO deaths shows (Abeysekera et al. 2005). Currently, mortality from 
anesthetic procedures is at least 1 to 10,000 over decades (Lienhart et al. 2006). PO mortality rates vary from country to country (Harrison 1978; Hovi-Viander 1980, Tiret et al. 1986; Pitt-Miller 1989; Tikkanen and Hovi-Viander 1995; Newland et al. 2002; Kawashima et al. 2003) and are fewer than 20 deaths per 10,000 anesthetics in developed countries. However, Brazilian studies showed higher PO mortality rates, from 19 to 51 deaths per 10,000 anesthetics (Bainbridge et al. 2012). Perioperative deaths (PODs) affect neonates, children under 1 year, and elderly male patients with comorbidity. Emergency surgeries and general anesthesia and cardiac, thoracic, vascular, gastroenterologic, pediatric, and orthopedic surgeries are considered at risk. Perioperative mortality rates, are higher in developing countries, while anesthesia-related mortality rates are similar, and these data may be useful for deaths prevention. More recently, meta-analysis using standardized reporting forms created by the American Society of Anesthesiologists (ASA) for identifying studies for inclusion and extracted informations (year, country of origin, and method of data collection) taken into account, with the object to identify anesthetic sole mortality (anesthetic-associated mortality (AAM)) and anesthesia-contributory mortality (Table 1). Total PO mortality (commonly considered as "death from any cause and cardiac arrest (CA)) has also interest in this field. Globally, there is strong evidence of reduction in anesthetic-related and perioperative mortality over the past 50 years, despite the increasing patients ASA risks (Table 2) and decreasing of CA in the perioperative setting (Braghiroli et al. 2017). Developing countries are affected two or three times more by anesthetic-related and perioperative mortality, if compared with developed countries (Avidan and Kheterpal 2012). Early and late mortality are also considered (Stefani et al. 2018). These data lead to a prior effort to reducing total perioperative and anesthetic-related mortality by preventive measures in those countries.

\section{Main text}

Definitions of anesthetic perioperative-related mortality and classifications

A generally accepted definition of the anesthesia-related death still remains one of the major concerns in forensic pathology (Deshpande 2011). As observed, the terms "operative deaths," "intra-operative," and "anesthetic deaths" are usually still applied inaccurately within the medicolegal literature (Saukko and Knight 2016; Di Maio and Di Maio 2001) (Table 1). Iatrogenesis, defined as illness resulting from errors (culpable or not) committed by physicians or other health care professionals, may include any

Table 1 Classification of perioperative deaths and possible medico-legal conclusions about health care professionals' responsibility

\begin{tabular}{|c|c|c|c|c|}
\hline DEFINITIONS & EXPLANATION & CAUSE(s) & $\begin{array}{l}\text { COMPLICATIONS/ } \\
\text { CONSEQUENCES }\end{array}$ & $\begin{array}{l}\text { ROOT CAUSES } \\
\text { ANALYSIS }\end{array}$ \\
\hline $\begin{array}{c}\text { ACD } \\
\prod \\
\begin{array}{c}\text { Peri-operative } \\
\text { deaths }\end{array}\end{array}$ & $\begin{array}{l}\text { Mortality due to disease } \\
\text { or injury, during surgery } \\
\text {-anesthetic activities }\end{array}$ & $\begin{array}{c}\text { Primary } \\
\text { Or } \\
\text { Contributing }\end{array}$ & $\begin{array}{l}\text { Worsening of cardiovascular/ } \\
\text { respiratory/nervous } \\
\text { balance or collapse } \\
\text { Unexpected death of inward patient }\end{array}$ & $\begin{array}{l}\text { Conclusive } \\
\text { Exclusion of } \\
\text { culpable role of } \\
\text { Human factors } \\
\text { (Natural deaths) } \\
\text { Possible culpable } \\
\text { role of } \\
\text { Human factors } \\
\text { and/or } \\
\text { preventable } \\
\text { Equipment / } \\
\text { System failure }\end{array}$ \\
\hline $\begin{array}{c}\text { AAD } \\
\rrbracket \\
\text { Anesthetic } \\
\text { deaths }\end{array}$ & $\begin{array}{l}\text { Mortality directly caused } \\
\text { by anesthetic activities }\end{array}$ & Primary & 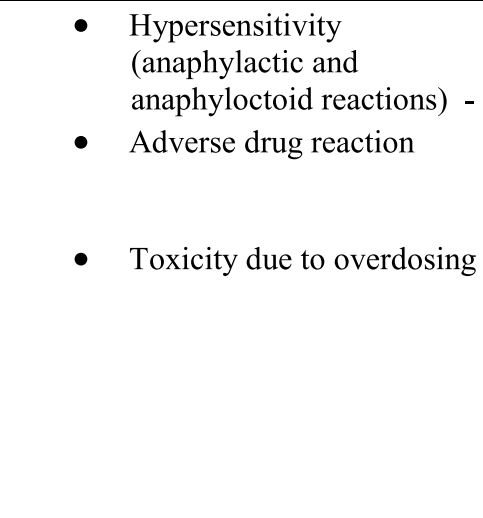 & 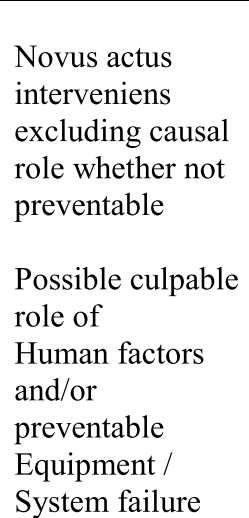 \\
\hline
\end{tabular}


Table 2 Perioperative mortality rate according to time after surgical interval, age, and patients' ASA status

\begin{tabular}{|c|c|c|c|c|c|}
\hline Age & $\begin{array}{l}\text { Mortality rate per 100,000 } \\
\text { anesthetic procedures }\end{array}$ & & $\begin{array}{l}\text { by ASA } \\
\text { s }\end{array}$ & $\begin{array}{l}\text { Early mortality rate } \\
(<24 h)^{* *}\end{array}$ & $\begin{array}{l}\text { Late mortality rate } \\
(\leq 30 \text { days })^{* *}\end{array}$ \\
\hline $0-7$ years & $0.60(0.12-3.2)$ & I & $0.40(0.12-0.81)$ & 76 & 243 \\
\hline $8-15$ years & $1.20(0.30-3.2)$ & $\|$ & $5.0(1.6-9.1)$ & & \\
\hline 16-39years & $0.52(0.24-0.93)$ & III & $27.0(12.0-44.0)$ & & \\
\hline 40-74 years & $5.20(2.7-8.1)$ & IV & $55.0(1.1-130.0)$ & & \\
\hline$\geq 75$ years & $21.00(8.3-34.0)$ & & & & \\
\hline
\end{tabular}

Adapted from Lienhart et al. (2006)

**Incidence of death analyzed in the perioperative period of 11.562 procedures

negative consequences of invasive procedures (Lau 2005). Such events involve comprehensively perioperative and non-perioperative fatalities. The use of such a broad definition allows for subtle separation of natural and unnatural death, at least from the prospective forensic pathology (Madea and Argo 2014). Critical areas of anesthesia-related mortality are airway management difficulties and cardiocirculatory disorders, some related to anesthetic drugs, while others occur as a consequence of aging synergistically and preexisting pathologically, which requires a carefully investigation and evaluation for professional health care responsibility (McCarthy 1999). Selective literature research in PubMed data bases, concerning perioperative and anesthetic deaths and medical responsibility, was performed. As a result, a total of 239 papers was included and considered, as related to selected topic (perioperative, anesthetic, and medico-legal). Following analyzed literature, iatrogenic deaths involve the following categories.

\section{Inevitable mortality caused by an illness or lesion(s) for} which surgical/anesthetic was performed

From the medico-legal point of view, both injury and/or disease(s) have to be considered as principal and proximate cause of death, or predominantly procedural in nature. The original condition is certified by some medico-legal systems as the cause of death by omitting the surgical intervention. Many of these fatalities can be regarded as mors in tabula, regarding patients in extreme physical condition, with unfavorable surgical outcome. In this regard, the well-known classification of the American Society of Anesthesiologists (ASA), which is used worldwide, specifies different risk levels attributable to increasing seriousness of patient's physical condition. Under the ASA classification, mortality risk can also be stratified by age.

Caused by a disease or abnormality not done regarding procedure, nor resulting from wrong technical surgery, or related, as inevitable complications (perioperative cardiac and cerebrovascular events)

Determined by the conditions or illness requiring invasive/surgical procedure, even rare and/or undiagnosed illness or conditions to death (Abate et al. 2014; Maresi et al. 2013; Maresi et al. 2006; Rancati et al. 2018), especially preventable conditions and complex clinical interactions, account for overall $90 \%$ of PODs. Myocardial infarction (MI) in the perioperative period, even in patients without medical history or ischemic heart disease, takes import role. In addition to the usual pathologic findings, cardiovascular factors or metabolic, hyperlipidemia, and/or wrong lifestyle are usual revealed (Serretta et al. 2018). It is not a simple matter to resolve, though this question involves the field of forensic investigation, the causative role of that illness and pathologies distress, in terms of causation or not influencing role. Within incidence rates, risk of early PODs in patients undergoing non-cardiac surgery is less than $1 \%$, while in patients with coronary risk factors for heart disease, it accounts for 17\% (Ashton et al. 1993).

PO myocarditis is less common and often presents as an unexplained viral infection or an adverse drug reaction (ADR), rarely reported as fatal giant cell myocarditis, as expression of foreign body reaction caused by cardiac valve surgery or coronary artery bypass (Rashid and Williams 1994). Is a matter of debate whether deaths after events such as stent embolism and re-stenosis after percutaneous transluminal coronary angioplasty, with resultant worsening of the underlying myocardial ischemia or extension of the original MI, should be considered to be iatrogenic in nature, at least from a forensic perspective. Similar considerations are to be applied to the occurrence of cerebral vascular stroke occurring after variable perioperative time intervals. Higher risk (about twice) of stroke is reported in patients undergoing coronary artery bypass grafting affected by unstable angina or non-Q-wave myocardial infarcts (Josefson 2001).

\section{Complications of general and spinal anesthetic}

Deaths due to anesthetic errors seem to be less frequent than those caused by surgical or invasive procedure but usually with worsening consequences. Contributing effect of anesthesia to death generally varies to $1: 1700-1: 10,000$ operations (Lau 2005). Lau reported in his coronial autopsy practice only six deaths attributable to adverse anesthetic events out of a total of $572 \mathrm{PO}$ autopsies (Lau 2000). When deaths occur within $24 \mathrm{~h}$ after administering 
anesthesia, medico-legal questions are almost always an issue. With regard to relevant causes and mechanisms, most authors emphasize two fundamental pathways responsible for most deaths: missing control of respiratory airways/exchange and management of circulatory homeostasis (Moar 1996; Lagasse 2006). Further, each can be subdivided as errors in airway control and ventilation and defects in blood volume management and arrhythmic trouble control. Causal chain of the anesthesia-related deaths can be explained by a "tree" representation, which appears of useful application in medico-legal context regarding general anesthesia (Fig. 1).

\section{Failure in airway management}

Anesthesia management determines morbidity and mortality, as investigated in survey studies (Arbous et al. 2005). Data from many sources can be analyzed: patient claims and related requests for reimbursement and questionnaires returned by anesthetists often, as well as national surveys committed by the Health Minister all can provide valuable information (Van der Walt et al. 1993;
Clergue et al. 1999; Morray et al. 2000; Jimenez et al. 2007; Bhananker et al. 2007).

Within that data, the lack of airway management is the most common general cause of ACD, and two-thirds of these result from complications of endotracheal intubation (Hofmann et al. 2002; Auroy et al. 2009), accidental esophageal intubation is a common mistake in inexperienced anesthetists (Frova and Tuzzo 1999) or delay in intubation (Bono et al. 2008). The most common of the endotracheal mishaps is unsuccessful intubation after muscle relaxant administration (Auroy et al. 2009). Inadequate pre-anesthetic examination does not prevent unexpected anatomical or pathological abnormality (El-Ganzouri et al. 1996; Paix et al. 2005, Lee et al. 2006); disconnection and dislodgement of the endotracheal tube, endotracheal tube mishap determined by endotracheal tube obstruction, tube kinking or cuff herniation, tension pneumothorax, and errors of oxygen cylinder causing the patient to breathe an anoxic gas mixture lead to anoxia; more commonly, anoxia may be determined by pus, blood, or secretions obstacle in breath (Tourtier et al. 2004) vomiting, regurgitation, and aspiration (Neelakanta

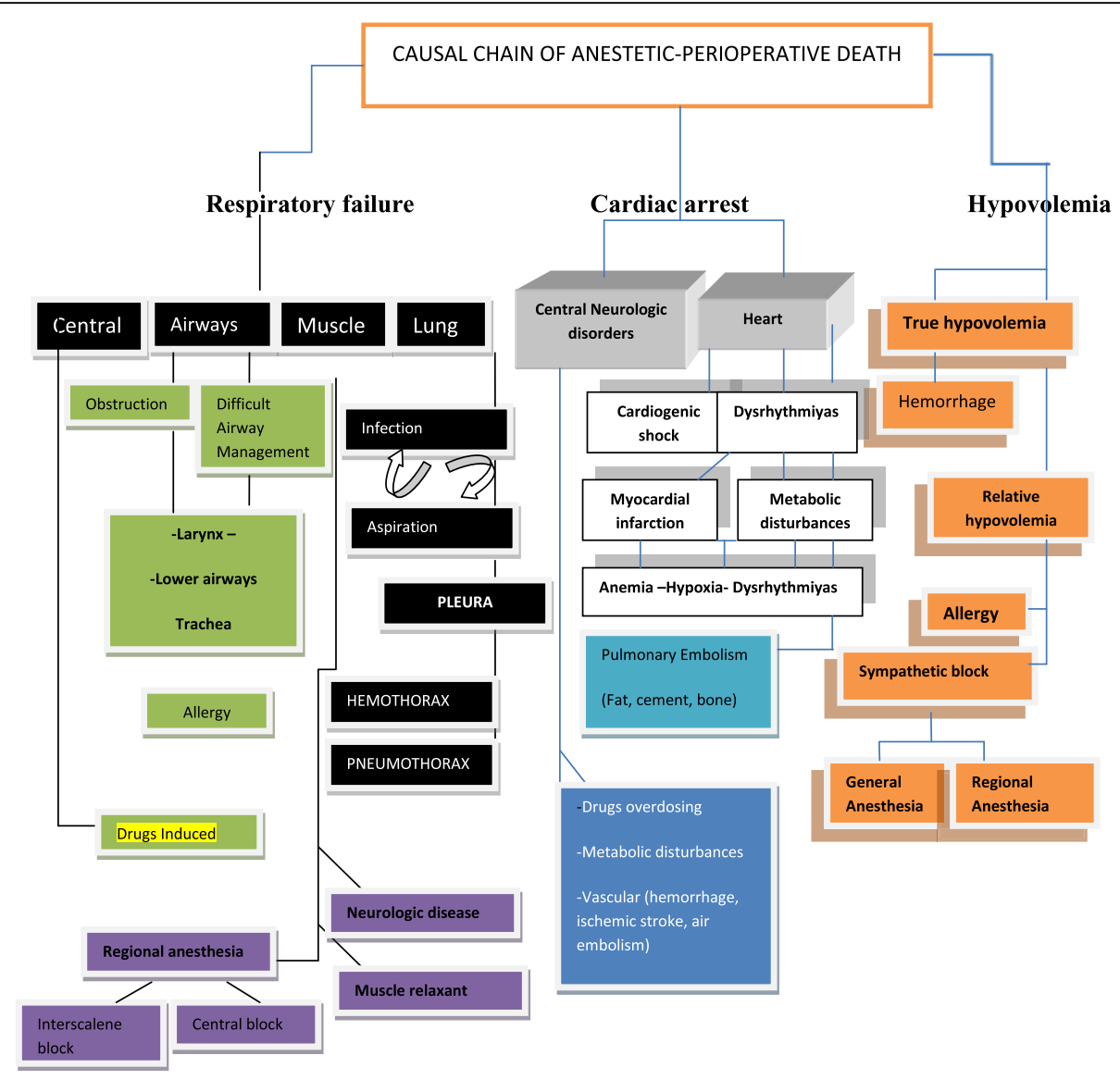

Fig. 1 Description of causal and consequences related to anesthetic-perioperative death. Legend: Summarizes common aspects of interest regarding pathology in $A A D$ and $A C D$ 
and Chikyarappa 2006). Secondly, inadequate pulmonary ventilation during anesthesia accounts for about $20 \%$ of anesthetic-related deaths. The delay in treating attempted reversal of neuromuscular blockade is a common mistake. To report the post-anesthetic respiratory depression after fentanyl administration, misdiagnosis of the post-operative restlessness of anoxia as being due to pain, with wrong administration of more narcotic (Preckel and Bolten 2005). In studies of Tiret et al. (1986), errors commonly involved were difficulty to maintain oropharyngeal airway during recovery to full consciousness of patients after anesthesia and fluid overload in the immediate post-anesthetic recovery phase, causing pulmonary edema. In accord with Harrison (1978), the occurrence of these tragic errors requires a careful recognition of medical instructions to health care professionals, missing adequate communication teamwork (Cook and MacDougall-Davis 2012).

\section{Inadequate balance of the patient's circulatory system}

Around $35 \%$ of ACD are due to failure in control circulatory homeostasis, and these can be further attributed to blood volume regulation (hypo- or hypervolaemia) and arrhythmia management; CA due to hypovolaemia is preceded by functional myocardial ischemia; inadequate cardiac venous return may cause intractable post-induction hypotension; and commonly excessive blood transfusion and/or electrolyte components, causing cardiac overload and pulmonary edema, may lead to CA. Anoxic or anoxic/ ischemic encephalopathy may result from $\mathrm{CA}$ during application of cardiopulmonary resuscitation $(\mathrm{CPR})$ and this imposes to supervise regaining consciousness of patients, as Lunn and Mushin (1982) first stated, the surveillance period should be extended to the sixth post-anesthetic day. In a Danish study (Hove et al. 2007), post-induction hypotension following administration of thiopentone, bupivicaine (epidural/spinal anesthesia) was a relevant anesthetic complication causing collapse. Bradycardia or CA was attributed to suxamethonium, succinylcholine, and neostigmine and ventricular fibrillation to halothane, intravenous digoxin, isoxsuprine, and droperidol. As reported by Pitkänen et al. (2013) the majority of patients suffering serious complications related to spinal and epidural blocks were the elderly having comorbidities.

\section{Summary of the most common, potentially lethal, general anesthetic complications}

Most publications on the subjects include the following potentially lethal anesthetic complications (Solazzi and Ward 1984):

- Hypoxic-ischemic encephalopathy and brain death due to oxygen deficiency by failed intubation (caused by inexperienced operator or technical difficulties due to anatomic abnormalities), misplacement of the endotracheal tube, wrong oxygen sources, now minimized by modern anesthesia machines; these complications are classified by inclusion criteria and by severity of harm using National Audit Project of the Royal College of Anesthetists and Difficult Airway Society (Cook and MacDougall-Davis 2012).

- Airway obstruction, resulting from bleeding or secretions or foreign bodies. Problems with the airway and/or ventilation are the most likely causes of anesthetic mishaps. They often begin as slight respiratory embarrassment that progress to hypoxia and hypercarbia, and then degenerate into cardiovascular crises. Unfortunately, the adequacy of ventilation is more difficult to assess than alterations in the cardiovascular system. The pulse oximeter and the capnograph have markedly improved respiratory monitoring compared to the rather crude assessments of the past which were based upon observation of the reservoir bag, chest excursions, patient color, and auscultation of breath sounds (Cook and MacDougallDavis (2012). Mechanical obstruction of the airway by the tongue is very common and easily managed if recognized. Enlarged tonsils, edema, pharyngeal gauze partition, and foreign bodies are also risk factors for obstruction. Repositioning the head, insertion of an oral or nasopharyngeal airway, performing direct laryngoscopy, endotracheal intubation, or cricothyrotomy may be necessary to alleviate mechanical obstruction (Warner et al. 1993). Secretions, irrigation solution, blood, and surgical debris may initiate laryngospasm. It is important to remember that laryngospasm is a protective reflex that seals the entrance to the tracheobronchial tree to foreign matter. During partial or incomplete laryngospasm, high-pitched "crowing" sounds are produced on inspiration; no sounds are produced during a total or complete laryngospasm. Suctioning deeply into the posterior pharynx and the gentle application of positive pressure oxygen is the initial treatment. Anesthesia may also be deepened to decrease laryngeal irritability. If oxygen saturation drops significantly, a small intravenous dose of succinylcholine (5-10 $\mathrm{mg}$ ) may be given to relax the laryngeal muscles and permit positive pressure ventilation. Early diagnosis and aggressive treatment of laryngospasm are imperative, as a succinylcholine administration in the face of hypoxia and hypercarbia is associated with profound bradycardia and asystole.

- Aspiration of gastric contents or contrast medium. Aspiration of foreign bodies, such as teeth and bone fragments, is a recognized danger during dental procedures performed under general anesthesia when endotracheal intubation is not used to protect the airway. A properly positioned pharyngeal gauze 
partition and the constant availability of a highvolume evacuation system and Magill forceps are necessary to decrease this risk. Aspiration of at least $25 \mathrm{~mL}$ of gastric contents of a low pH (2.0) is required to produce serious morbidity. Management of aspiration includes vigorous suctioning of the pharynx and administration of $100 \%$ oxygen.

- Bronchospasm that must be included in any differential diagnosis whenever ventilatory difficulties are encountered. Whether the consequences of asthma, histamine release, anaphylaxis, airway manipulation and stimulation, or aspiration, it must be recognized early and vigorously treated. Unlike laryngospasm, bronchospasm is not protective. Increased airway pressures and significant wheezing during bronchospasm may be accompanied by severe hypoxemia and hypercarbia. Halothane produces bronchodilation but unfortunately sensitizes the myocardium to the arrhythmogenic effects of the beta-adrenergic bronchodilators. Glucocorticosteroids may also be effective for bronchospasm, but their prolonged onset times render them ineffective in managing the initial emergency (Rosenberg and Weaver (1991).

- Side effects of neuromuscular blockade depend on excessive, or duration; induction of anesthesia with thiopentone, pre-medication with trichloroethylene and atropine is believed to cause cardiorespiratory collapse.

- Malignant hyperthermia is a rare autosomal dominant condition that predisposes to sudden uncoupling of oxidative phosphorylation, with potentially lethal hyperthermia. Mutations in the genes coding for the skeletal muscle ryanodine receptor (RYR1) and alpha 1 subunit of the dihydropyridine receptor (CACNA1S) have been identified as causative for malignant hyperthermia $(\mathrm{MH})$. It is most likely to occur when known triggering agents (use of volatile inhalation anesthetics like halothane and certain muscle relaxants (e.g., suxamethonium, succinylcholine) are used. Clinically, malignant hyperthermia is usually first manifested as an unexplained, progressive tachycardia and an elevation in end-tidal carbon dioxide. Masseter muscle spasm after the administration of succinylcholine may also signal the onset of malignant hyperthermia. Muscle rigidity, cyanosis, dysrhythmias, and elevated temperature are also noted. In addition to the contracture test, requiring muscle biopsy sample, the use of metabolic test may indicate susceptibility to malignant hyperthermia, as susceptible individuals will have a considerably higher intramuscular $\mathrm{pCO} 2$ than controls (Anetseder et al. 2001).
- Halothane hypersensitivity disorder has an estimated incidence of 1:6000 to 1:600,000 anesthetic procedures and may be associated to worst consequences of halothane-induced hepatitis, or massive hepatocellular necrosis, after repeated exposure to the agent (Gelven et al. 1996).

Halothane hypersensitivity is mediated by the immune sensitization of susceptible individuals. Halothane, enflurane, isoflurane, and desflurane are metabolized through the metabolic pathway involving cytochrome P-450 2E1 (CYP2E1) and produce trifluoroacetylated components, some of which may be immunogenic.

- Lethal effect of propofol (alkylphenols), a sedativehypnotic agent that is the most commonly used intravenous agent for induction of anesthesia and for sedating mechanically ventilated patients in intensive care units, is now increasingly being used for conscious sedation during endoscopic procedures. Propofol is an extremely rapid-acting intravenous anesthetic, and its advantages include less residual post-operative sedation and less psychomotor impairment than the barbiturates, with low incidence of nausea and vomiting. Propofol produces dosedependent cardiovascular and respiratory depression with a profile similar to methohexital (Procaccianti et al. 2017). It has been associated with fatal heart failure both in children and in adult patients with head injuries (Maas et al. 2018). The propofol infusion syndrome includes myocardial failure, metabolic acidosis, and rhabdomyolysis in children receiving propofol infusions for more than $48 \mathrm{~h}$ (Cremer et al. 2001).

\section{Spinal anesthesia fatalities}

Spinal anesthesia is one of the most used anesthetic techniques, believed to be very safe, though severe complications may occur (Ishiyama et al. 2012). The first cases of CA occurring after spinal block anesthesia were reported in the 1940s and since then, the ability of spinal anesthesia to cause cardiopulmonary arrest was considered (Arruda et al. 2011). With regard to the etiology of cardiopulmonary arrest, Caplan et al. (1988) analyzed 14 episodes of unexpected CA during spinal anesthesia in healthy patients (physical status I and II ASA classification). The highest level of sensorial blockade achieved in any of the cases was T4; 12 out of the 14 patients were sedated and not adequately monitored. Despite cardiopulmonary resuscitation, six deaths were observed, with severe consequences in eight survivors. Lovstad et al. (2000) reported CA preceded by bradycardia of a 17-year-old patient, ASA I, underwent knee arthroplasty under spinal anesthesia. Probably because death is such a rare occurrence, the 
available data is contradictory, and the incidence rate is not really known. Investigators have reported rates ranging from 1.3 to 18 cases in 10,000 spinal anesthesias. Auroy et al. (2009) described an incidence of spinal anesthesia-related CA of $6.4 \pm 1.2$ in 10,000, significantly higher than combined rates reported for epidural anesthesia and peripheral blockades together $(1.0 \pm 0.4$ in 10,000 procedures), similarly reported by Pollard et al. (2001) during spinal anesthesia (0.03\%) and epidural anesthesia $(0.01 \%)$. Whatever the true rate, it is clear that $\mathrm{CA}$ is more common during general anesthesia, applied more commonly in complex, high-risk surgeries performed on. Respiratory depression or hypoxemia induced by sedative drugs are not reviled by Lovstad et al. (2000) in cases of primary asystole; other authors have shown that the majority of patients who experienced CA had not received sedative drugs (Liguori and Sharrock 1997). Mechanisms of bradycardia or asystole induced by spinal anesthesia are still controversial, but absolute or relative increase in activity of the parasympathetic nervous system lead patients with increased vagal tone at an elevated risk of developing those complications (Kumari et al. 2014).

Reduction of blood pressure and central venous pressure are effects of spinal block anesthesia related to the sympathetic nervous system blockade. Sensorial blockade in T4 can determine a blockade of all cardio-accelerator fibers (T1-T4), with progressive reduction in heart rate. Sympathetic blockade at the T1 level or above results in increased vagal tonus, which causes negative inotropic, chronotropic, and dromotropic changes without opposition from the sympathetic nervous system. A second reflex is attributed to mechanoreceptors, in the right atrium and ventricle, and baroreceptors, in the right atrium and vena cava. The third reflex is caused by mechanoreceptors in the infero-posterior wall of the left ventricle, whose stimulation increases activity in the parsympathetic nervous system and inhibits the activity of the sympathetic nervous system, producing bradycardia, systemic vasodilation, and hypotension. All these reflexes involve an increase in autonomic-vagal response (Gratadour et al. 1997), ranging from flow imbalance to CA. It is remarkable that the level of sensorial blockade in elderly patients is usually higher than that of young adults given the same dose of local anesthetic. Overdose of local anesthetic by subarachnoid route is a known cause of CA in elderly patients (Auroy and Benhamou 2001). Potent sympathomimetic agent is the first treatment option to increase coronary perfusion pressure, which increases peripheral vascular resistance, diastolic pressure, and coronary perfusion pressure, improving cerebral blood flow, and the use of mixed agents ( $\alpha$ - and $\beta$-adrenergic) is effective in increasing blood pressure, with less significant increase in systemic vascular resistance. Obviously, from a medicolegal perspective, prevention and treatment of potentially avoidable consequences have to be the main consideration (Sheppard and Anandampillai 2019).

Whatever the true number, the mortality differential between spinal and general is almost certainly declining as a result of increased knowledge of the physiology of spinal anesthesia, together with the use of less toxic local anesthetics and improved monitoring during spinal anesthesia (Patil et al. 2019; Finsterwald et al. 2018).

\section{Adverse drug reactions (ADRs) and anesthesia}

An adverse drug reaction (ADR) is an unwanted or harmful reaction experienced following the administration of a drug or combination of drugs under normal conditions of use and is suspected to be related to the drug and is responsible for the deaths of some 0.1 and $0.01 \%$ of medical and surgical inward patients, respectively; Lau (Lau 2000) during a 5-year period (1999-2003) reported fatal ADRs range between 0.3 and $0.5 \%$ of coronial autopsies. In medico-legal context suspicious cases of fatal ADR have to be assigned to type A reactions as being pharmacological, or type B (idiosyncratic). The type A (about $80 \%$ of ADRs) are dose-dependent with reversible effects of drug intake; the $B$ type is usually largely unpredictable and unpreventable. Type A reactions relay to the innate toxicity of a therapeutic drug, or from drug interactions used in combination. Extreme age of life and comorbidity determine a considerable risk of ADR. Type B reaction, less common, accounting for ADR-related deaths, is associated with various complex immunologic (e.g., anaphylaxis), metabolic (e.g., CYP2D6 deficiency), cell receptor (e.g., malignant hyperthermia), and multifactorial pathogenic mechanisms (e.g., halothane-induced hepatitis).

The majority of fatal ADRs (intended as perioperative anaphylaxis) that come to forensic attention are usually idiosyncratic reactions occurring around the time of surgery/anesthesia, with the incidence of $1 / 10,000$ of patients suffering surgery, often using neuromuscular blockers.

Pathological effects are massive hepatocellular necrosis, skin or mucocutaneous drug reactions (e.g., StevensJohnson Syndrome), toxic epidermal necrolysis complicated by sepsis, coagulopathy, and eventual multiorgan failure.

This subset of anesthetic-related deaths also includes overdose of drugs administered during general or local anaesthesia. Some cases of sudden death after injection of lidocaine to perform local anesthesia are occasionally reported in forensic literature (Hasegawa et al. 2008). They are related to iatrogenic effects, with different implications for physician liability, mostly depending on the demonstration that a true overdose was administered.

\section{Anaphylactic deaths (ana- = beyond; gr. fülaxis = defense)}

Despite the increasing frequency of perioperative allergic reactions, probably caused by the increase in surgical procedures performed under anesthesia and the growing 
complexity of drugs used, there is still a lack of accurate epidemiological data. ADRs are not uncommon: most of the data on perioperative prophylaxis come from the registry of Australia, France, New Zealand, Spain, and UK. Although anaphylaxis is a rare event $(1: 10-20,000$ general anesthesia, 1: 6500 in the case of anesthesia with use of Neuromuscular blocking agents (NMBA), it is often associated with a high mortality rate (3-9\%) and major sequelae, especially if not properly treated (Calapai et al. 2016).

The incidence of perioperative anaphylaxis can vary depending on the degree of exposure of the environment population to hazardous substances (Ewan et al. 2009). In Norway, the frequency of this condition is due to the fact that NMBA decreased since it is a cough syrup based on pholcodine (an analogue of morphine) able to sensitize the population was retired from the market in 2007. Medications containing pholcodine were withdrawn from the Swedish market in 1989, in accord with new published guidelines for the treatment of cough. The comparison of epidemiological data between Norway and Sweden showed that anaphylactic reactions to NMBA were over six times more common in the Norwegian population than Swedish (Kroigaard et al. 2007). Incidence of anaphylaxis to latex dramatically increased everywhere in Europe over the last decades and more recently appears to have reduced by primary prevention measures (interventions in latex-free environment). The incidence of anaphylaxis from chlorhexidine seems currently on the rise, while anaphylactic reactions to colloids remain relatively stable (around 4\%). Immune reactions to local anesthetics are still rather rare, representing less than $1 \%$ of the possible reactions adverse to these drugs; the majority of such reactions are caused by accidental intravascular injection, leading to side effects, especially on the cardiovascular and central nervous. Systemic allergic reactions to opioids are uncommon, though it should be noted that morphine causes mast cells to release histamine, while synthetic narcotic do not exert this effect. The prevalence of allergic reactions to corticosteroids varies from $0.5 \%$ to $5 \%$ and has so far been reported in the literature anaphylaxis anesthetics inhalers (Venturini et al. 2006). There is little information about the epidemiology of anaphylactic reactions in the PO of children surgery. A study conducted at a pediatric hospital department reported 68 cases of children who presented anaphylaxis during anesthesia (Karila et al. 2005). It was recognized as an IgE-mediated mechanism in 51 patients; 31 cases $(60.8 \%)$ were caused by NMBA, 14 cases from latex (27\%), 7 cases by colloids (14\%), 5 cases by opiate (9\%), and 6 cases by hypnotics (12\%), with prevalence of vecuronium within the neuromuscular blocking agent reactions. Twenty-three of the 31 children demonstrated cross-reactivity between NMBA, particularly between vecuronium, atracurium, and pancuronium. Allergic reactions during anesthesia generally have variable frequencies in different countries and in different series between. The reactions rate ranges between $1 /$ 10,000 and $1 / 13,000$, and $3-9 \%$ of these cases ultimately proved fatal (Chen et al. 2016). Adults between 30 and 50 years, mostly female (female/male ratio $=3-4: 1$ ) seem most vulnerable. The frequency with which the different drugs used in general anesthesia cause allergic reactions varies in different series. Muscle relaxants are responsible for more than half of anaphylactoid reactions (up to 70\%) followed by hypnotics, colloidal plasma substitutes, benzodiazepines, and opiates (Barke and Hough 1993). A very important role in determinism of these reactions is that latex is implicated in over $10 \%$ of cases. Allergic reactions to non-depolarizing muscle relaxants, including $\mathrm{d}$-tubocurarine, metocurine, pancuronium, gallamine, atracurium, and vecuronium, are the most serious, affecting mainly females. These reactions seem to be due to the nonspecific release of mediators and hypersensitivity induced by quaternary ammonium ions antigenic determinants shared by all members of this class of drugs. The frequency and severity of anaphylaxis to non-depolarizing muscle relaxants finds its explanation in the structural features of the molecule and in the ease of contact with the quaternary ammonium ions in the environment (acquired latent sensitization). Substances containing quaternary ammonium ions are present in eye drops, antiseptics, laundry detergents, food preservatives, and cosmetics. The universality of these agents within the environment raises the possibility of a reaction even at the first anesthesia. It has been found that $80 \%$ of subjects sensitized to muscle relaxants have specific IgE to these drugs even 14 years after a shock. Among the factors favoring the anaphylactoid reactions in general anesthesia, common food should also be mention. Within foods, potatoes, tomatoes, and aubergines may contain naturally occurring solanaceous glycoalkaloids (which are naturally occurring insecticides that remain in the body for several days after ingestion). The inhibition of butyrylcholinesterase and acetylcholinesterase by solanaceous glycoalkaloids may cause persistence of anesthetic agents and muscle relaxants in the body and a prolonged clearance time (last as long of 5-10 h (Tanne 1998).

A cascade of signs (hypotention, pruritis, urticaria, tightness in the chest, wheezing) and symptoms (faintness, shortness of breath, collapse) are seen during anaphylactic attack. Anaphylactic deaths develop usually immediately or within $20 \mathrm{~min}$. After exposure to a particular antigen, death usually occurs within 1-2 h. A fatal anaphylactic reaction results in acute respiratory distress or circulatory collapse (Baido and Pham 2013). Obstruction of the upper airway can be caused by pharyngeal or laryngeal edema of the lower airway, by bronchospasm with contraction of the smooth muscle of 
the lungs, vasodilation, and increased capillary permeability. CA may be caused by respiratory arrest; chemical mediators of anaphylaxis may directly cause shock caused by a combination of intravascular fluid loss from edema and vasodilatation. Anaphylactic shock due to an acute immediate allergic reaction may be suspected when unusually resistant hypotension is encountered. It may be accompanied by bronchospasm, rash, edema, and hives. Epinephrine in intravenous increments plus $100 \%$ oxygen are the immediate treatment, doses of 1 $\mathrm{mg}$ of epinephrine may be necessary. The sooner anaphylaxis is diagnosed and treatment instituted, the better the outcome and the less chance of total cardiovascular collapse and complete airway obstruction (Rosenberg and Weaver 1991). Unfortunately, pathological investigations both macroscopically and microscopically and ancillary laboratory investigations are often of poor relevance (Edston and van Hage-Hamsten 1998). In fact, autopsy findings are often nonspecific, like upper airway edema, but rarely complete obstruction of the airway and in suddenly occurring deaths, and the only finding might be visceral congestion. In the study of Roberts and Pumphrey (2001) of 56 anaphylactic deaths with autopsy investigation, 16 deaths were caused by food allergy and 13 caused by respiratory arrest. In 8 of 19 cases caused by insect venom and 12 of 21 caused by drugs reactions, shock without breathing symptoms occurred. The authors reported laryngeal or pharyngeal edema in $8 \%$ and $49 \%$, respectively, of individuals who died immediately. Emphysema caused by the bronchoconstriction might be present. Visceral and pulmonary congestion, edema, and pulmonary hemorrhage are present but are nonspecific. Twenty-three of 56 anaphylactic deaths had no macroscopic findings at autopsy. Microscopic examination may show edema in the respiratory mucosa, with infiltrate of eosinophils and epithelial desquamation. In anaphylactic deaths, the quantity of degranulated mast cells from tissues is with difficulty evaluated and, furthermore, mast cells are further difficult to identify in postmortem tissues. More recently, immunological methods to detect and quantify mast cell proteases (tryptase), made possible to diagnose or confirm anaphylaxis postmortem (Edston and van Hage-Hamsten 1998; Payne and Kam 2004).

Moreover, tryptase was found to be elevated in a few cases where anaphylaxis was not diagnosticated (Randall et al. 1995). In addition, it is important to consider that an increase of tryptase may be caused by postmortem diffusion from tissues into the blood. Patient's medical history comprehensive of therapeutic agent administration and circumstances of death plays an essential role when investigating suspected anaphylaxis (Edston and van Hage-Hamsten 2005; Byard 2017). As diagnostic tools, tryptase measurements, and analysis of allergen- specific immunoglobulin E antibodies, a panel of common allergens, therapeutic agents like penicillin or iodine-containing contrast, may be considered (Fineschi et al. 1999).

\section{Need for further perioperative quality control programs and its relevance for medico-legal evaluation}

Increasing subspecialization and advanced medical technology, by treating greater numbers of older and ill patients, explains the elevated risk of invasive procedure; fields of medico-legal interest concerns now include relevant and new problems regarding unexplained PODs. Epidemiological data indicated that the "classical" complication (e.g., failure or mishap in airway management) have become more infrequent, and the anesthetic-associated death is usually multifactorial; also in the view of poor gross findings at autopsy of that occurrences, this cooperation is necessary to lead evidence and conclusions about death (O'Grady 2003). Considering these aspects, cases of res ipsa loquitur remain individual, and a broad spectrum of post mortem molecular investigative possibilities must be considered facing with perioperative deaths, by pathologists, anesthesiologists, and surgeons in synergy. Database retrospective analysis and evaluation of root cause analysis related to PODs, as implemented in different health systems (Norway, French, New Zeland, UK), showed useful strategies to reduce preventable avoidable deaths, f.i. in the field of PO medication errors (Nanji et al. 2016): worthy of mentioning adopted simple measures (as prefilled syringes) and facilitating system to report drug administration error by health care professionals.

In medico-legal field of interest, by contributing to explore why PO accident happens lead to simplify an audit process and manage distinct clinical responses and whether that can modify the adverse responses. In this view, a systematic interdisciplinary investigation which includes medico-legal evidence from autopsies, e.g., gross findings, ancillary laboratory investigations, and recent molecular autopsy indicating gene preventable diseases (Madea et al. 2010) may contribute to adopt strategies for patient safety in anesthetic-surgical practice. In the view of defense of the anesthesiologist (Lee et al. 2011), decisions about medical negligence are based on standard-of-care issues that imply also an indication about guidelines application or not, again within medico-legal approach (Rini et al. 2018).

\section{Conclusions}

The preventable perioperative complications are evaluated to improve the safety of health care, including also the medical-law point of view; the adaptation of monitoring techniques and the adoption of guidelines have already contributed significantly to this goal (Abeysekera et al. 2005) reducing mortality, and the detailed 
investigation of actual or suspected iatrogenic deaths is a crucial piece for the continuous improvement of health care. Evidence gathered from postmortem investigation of $\mathrm{PO}$ deaths and audit program (centered on incidence, causes and consequences, included into a critical incident datasets) systematically adopted by health care systems may indicate an interdisciplinary, useful strategy of clinical risk management and support the decision about medical negligence.

\section{Abbreviations}

AAM: Anesthetic-associated mortality; ACDs: Anesthetic contributory deaths; ADRs: Adverse drug reactions; ARDs: Anesthetic-related deaths; ASA: American Society of Anesthesiologists; CA: Cardiac arrest; CPR: Cardiopulmonary resuscitation; MI: Myocardial infarction; NMBA: Neuromuscular-blocking agents; PO: Perioperative; PODs: Perioperative deaths

\section{Acknowledgements}

Not applicable

\section{Funding}

No funding for the research reported.

\section{Availability of data and materials}

Data sharing is not applicable to this article as no datasets were generated or analyzed during the current study.

\section{Authors' contributions}

AA conceived of this study and performed the draft; RB revised for drugs toxicological aspects; SBK partecipated in the design of the study, helped to drafting and editing language; and $\mathrm{SZ}, \mathrm{AL}$, and RR contributed to literature search and evaluation. All authors read and approved the final manuscript.

\section{Authors' information}

Antonina Argo MD is the head of the School of Specialization of Legal Medicine in the University of Palermo and a member of the local Ethics Committee. Stefania Zerbo MD is a specialist of legal medicine, a researcher of legal medicine, and an expert for clinical risk. Antonietta Lanzarone MD is a resident of legal medicine. Roberto Buscemi is graduate in organic chemistry, phD. Roberta Roccuzzo MD is a resident of legal medicine.

Steven Karch is an MD, FFFLM, fellow Forensic Science Soc. and consultant of forensic pathology and toxicology.

\section{Ethics approval and consent to participate}

Not applicable. This manuscript does NOT involve human participants, human data, or human tissue.

\section{Consent for publication}

Not applicable

\section{Competing interests}

The authors declare that they have no competing interests.

\section{Publisher's Note}

Springer Nature remains neutral with regard to jurisdictional claims in published maps and institutional affiliations.

\section{Author details}

'Department Pro.Mi.Se, Legal Medicine, School of Medicine, University of Palermo, Via del Vespro 129, 90127 Palermo, Italy. ${ }^{2}$ FFFLM, Consultant, PO Box 5139, Berkeley, CA, USA.

Received: 28 August 2018 Accepted: 21 April 2019

Published online: 14 May 2019

\section{References}

Abate D, Vella M, Alonge V, Serretta V (2014) Urothelial carcinoma in a pyelocaliceal cyst. Urol Int 81(4):249-252
Abeysekera A, Bergman IJ, Kluger MT, Short TG (2005) Drug error in anaesthetics practice: a review of 896 reports from the Australian Incident Monitoring Study database. Anaesth 60:220-227

Anetseder M, Hager M, Muller CR, Roewer N (2001) Diagnosis of susceptibility to malignant hyperthermia by use of a metabolic test. Lancet 359:1579-1580

Arbous MS, Meursing AEE, Van Kleef JW et al (2005) Impact of anesthesia management characteristics on severe morbidity and mortality. Anesthesiology 102:257-268

Arruda G, Limongi J, Sant'Anna de Melo Lins R (2011) Cardiopulmonary arrest in spinal anesthesia. Rev Bras Anestesiol 61:110-120

Ashton CM, Petersen NJ, Wray NP et al (1993) The incidence of perioperative myocardial infarction in men undergoing noncardiac surgery. Ann Intern Med 118:504-510

Auroy Y, Benhamou D (2001) Can we explain the high incidence of cardiac arrest during spinal anesthesia for hip surgery?: in reply. Anesthesiology 99:755

Auroy Y, Benhamou D, Péquignot F, Bovet M, Jougla E, Lienhart A (2009) Mortality related to anaesthesia in France: analysis of deaths related to airway complications. Anaesth 64:366-370

Avidan MS, Kheterpal S (2012) Perioperative mortality in developed and developing countries. Lancet 380:1038-1039

Baido BA, Pham NH (eds) (2013) Drug allergy: clinical aspects, diagnosis, mechanisms, structure-activity relationships. Springer-Verlag, New York, pp 59-61

Bainbridge D, Martin J, Arango M, Cheng D (2012) Perioperative and anaestheticrelated mortality in developed and developing countries: a systematic review and meta-analysis. Lancet 380:1075-1081

Barke KE, Hough B (1993) Opiates, mast cells and histamine release. Life Sci 53: 1391-1399

Bhananker SM, Ramamoorthy C, Geiduschek JM, Posner K et al (2007) Anesthesiarelated cardiac arrest in children: update from the Pediatric Perioperative Cardiac Arrest Registry. Anesth Analg 105:344-350

Bono G, Argo A, Zerbo S, Triolo V, Procaccianti P (2008) Cervical necrotizing fasciitis and descending necrotizing mediastinitis in a patient affected by neglected peritonsillar abscess: a case of medical negligence. J Forensic Legal Med 15:391-394

Braghiroli KS, Braz JRC, Rocha B, El Dib R, Corrente JE, Braz MG, Braz LG (2017) Perioperative and anesthesia related cardiac arrests in geriatric patients: a systematic review using meta-regression analysis. Sci Rep 7:2622. https://doi. org/10.1038/s41598-017-02745-6

Byard RW (2017) Anaphylaxis at autopsy. Forensic Sci Med Pathol 13:269-271

Calapai G, Imbesi S, Ventura Spagnolo E, Cafeo V, Milone L, Navarra M, Gangemi S (2016) Fatal anaphylactic shock ceftriaxone-induced in a 4-year-old. Child Pediatr Emerg Care 32:32-33

Caplan RA, Ward RJ, Posner K et al (1988) Unexpected cardiac arrest during spinal anesthesia: a closed claims analysis of predisposing factors. Anesthesiology 68:5-11

Chen X, Thong SY, Chong YY, Ng SY (2016) A review of perioperative anaphylaxis at a Singapore tertiary hospital. Singap Med J 57:126-131

Clergue F, Auroy Y, Pequignot F, Jougla E, Lienhart A, Laxenaire MC (1999) French survey of anesthesia in 1996. Anesthesiology 91:1509-1520

Cook TM, MacDougall-Davis SR (2012) Complications and failure of airway management. Br J Anaesth 109(S1):i68-i85

Cooper JB, Newbower RS, Kitz RJ (1984) An analysis of major errors and equipment failures in anaesthesia management: consideration of prevention and detection. Anesthesiology 60:34-42

Cremer OL, Moons KGM, Bouman EAC et al (2001) Long-term propofol infusion and cardiac failure in adult head-injured patients. Lancet. 357:117-118

Deshpande JK (2011) Cause and effect or conjecture? A call for consensus on defining "anesthesia-related mortality". Anesth Analg 112:1259-1261

Di Maio VJ, Di Maio D (2001) Intra-operative deaths. In: Di Maio VJ, Di Maio D (eds) Forensic pathology, 2nd edn. CRC Press, LLC, Boca Raton, pp 484-485

Edston E, van Hage-Hamsten M (1998) Beta-tryptase measurements post-mortem in anaphylactic deaths and in controls. Forensic Sci Int 93:135-142

Edston E, van Hage-Hamsten M (2005) Postmortem diagnosis of anaphylaxis. In: Tsokos M (ed) Forensic pathology reviews. Humana Press, Totowa, pp 267-281, 3

El-Ganzouri AR, McCarthy RJ, Tuman KJ, Tanck EN, Ivankovich AD (1996) Preoperative airway assessment: predictive value of a multivariate risk index. Anesth Analg 82:1197-1204

Ewan PW, Dugue P, Mirakian R et al (2009) BSACl quidelines for the investigation of suspected anaphylaxis during general anaesthesia. Clin Exp Allergy 40:15-31

Fineschi V, Monasterolo G, Rosi R, Turillazzi E (1999) Fatal anaphylactic shock during a fluorescein angiography. Forensic Sci Int 100:137-142 
Finsterwald M, Muster M, Farshad M, Saporito A, Brada M, Aguirre JA (2018) Spinal versus general anesthesia for lumbar spine surgery in high risk patients: perioperative hemodynamic stability, complications and costs. J Clin Anesth 46:3-7

Frova Z, Tuzzo D (1999) Anesthesia accidents: accidental esophageal intubation. Minerva Anestesiol 65:362-366

Gaba DM (2000) Anesthesiology as a model for patient safety in health care. BMJ 320:785-788

Gelven PL, Cina SJ, Lee JD, Nichols CA (1996) Massive hepatic necrosis and death following repeated isoflurane exposure: case report and review of the literature. Am J Forensic Med Pathol 17:61-64

Gratadour P, Viale JP, Parlow J et al (1997) Sympathovagal effects of spinal anesthesia assessed by the spontaneous cardiac baroreflex. Anesthesiology 87:1359-1367

Harrison GG (1978) Death attributable to anaesthesia. A 10-year survey (19671976). Br J Anaesth 50:1041-1046

Hasegawa M, Fujihara J, Takatsuka H, Chung HC, Takeshita H (2008) A case of sudden death after gingival injection of a therapeutic dose of lidocaine: distribution of lidocaine in whole blood and various tissues. Forensic Toxicol 26:41-44

Hofmann HS, Rettig G, Radke J, Neef H, Silber RE (2002) latrogenic ruptures of the tracheobronchial tree. Eur J Cardiothorac Surg 21:649-652

Hove LD, Steinmetz J, Christoffersen JK, Moller A, Nielsen J, Schimidt H (2007) Analysis of deaths related to anaesthesia in the period 1996-2004 from closed claims registered by the Danish Patient Insurance Association. Anesthesiology 106:675-680

Hovi-Viander M (1980) Death associated with anesthesia in Finland. Br J Anaesth $52: 483-489$

Ishiyama T, Shibuya K, Terada Y, Iwashita H, Masamune T, Kotoda M, Matsukawa T (2012) Cardiac arrest after spinal anesthesia in a patient with neurally mediated syncope. J Anesth 26:103-106

Jimenez N, Posner KL, Cheney FW, Caplan RA, Lee LA, Domino KB (2007) An update on pediatric anesthesia liability: a closed claims analysis. Anesth Analg 104:147-153

Josefson D (2001) Early bypass surgery increases risk of stroke. BMJ 323:185

Karila C, Brunet-Langot D, Labbez F et al (2005) Anaphylaxis during anesthesia: results of a 12-year survey at a French pediatric center. Allergy 60:828-834

Kawashima Y, Takahashi S, Suzuki M et al (2003) Anesthesia - related mortality and morbidity over a 5-year period in 2,363,038 patients in Japan. Acta Anesthesiol Scand 47:809-817

Kroigaard M, Garvey LH, Gillberg L et al (2007) Scandinavian Clinical Practice Guidelines on the diagnosis, management and follow-up of anaphylaxis during anaesthesia. Act Anesthesiol Scand 51:655-670

Kumari A, Gupta R, Bajwa SJ, Singh A (2014) Unanticipated cardiac arrest under spinal anesthesia: an unavoidable mystery with review of current literature. Anesth Essays Res 8(1):99-102

Lagasse RS (2002) Anesthesia safety: model or myth? A review of the published literature and analysis of current original data. Anesthesiology 97:1609-1617

Lagasse RS (2006) To see or not to see. Anesthesiology 105:1071-1073

Lau G (2000) Perioperative deaths: a further comparative review of coroner's autopsies with particular reference to the occurrence of fatal iatrogenic injury. Ann Acad Med Singap 29:486-497

Lau G (2005) latrogenic injury. In: Tsokos M (ed) Forensic pathology reviews. Humana Press Inc., Totowa, pp 351-439, 3

Lee A, Fan LTY, Gin T, Karramkar MJ, Ngan KWD (2006) A systematic review (meta-analysis) of the accuracy of the Mallampati test to predict the difficult airway. Anesth Analg 102:1867-1878

Lee LA, Stephens LS, Fligner CL, Posner KL, Cheney FW, Caplan RA, Domino KB (2011) Autopsy utilization in medicolegal defense of anesthesiologists. Anesthesiology 115(4):713-717

Lienhart A, Auroy Y, Péquignot F et al (2006) Survey of anesthesia-related mortality in France. Anesthesiology 105:1087-1097

Liguori GA, Sharrock NE (1997) Asystole and severe bradycardia during epidural anesthesia in orthopedic patients. Anesthesiology 86:250-257

Lovstad RZ, Granhus G, Hetland S (2000) Bradycardia and asystolic cardiac arrest during spinal anaesthesia: a report of five cases. Acta Anaesthesiol Scand 44:48-52

Lunn JN, Mushin WW (1982) Mortality associated with anaesthesia. Anaest 37:856

Maas A, Maier C, Iwersen-Bergmann S, Pilgrim JL, Di Rago M, Madea B, Hess C (2018) Propofol and propofol glucuronide concentrations in hair following medical propofol administration and in forensic death cases. Forensic Toxicol $36: 270-279$
Macintosh R (1948) Deaths under anesthetics. Br J Anaesth 21:107-136

Madea B, Argo A (2014) Certification of death: external postmortem examination. In: Madea B (ed) Handbook of forensic medicine. Handbook of Forensic Medicine, Wiley, Chichester, pp 57-74

Madea B, Saukko P, Oliva A, Mushoff F (2010) Molecular pathology in forensic medicine. Introduction. For Sci Int 203:3-14

Maresi E, Argo A, Portelli F, Busardò FP, Raoult D, Lepidi H (2013) Rare occurrence of whipple disease in a young female patient with a fatal outcome. Egypt J Forensic Sci 3(3):85-91

Maresi E, Argo A, Spanò GP, Novo GM, Cabibi DR, Procaccianti PG (2006) Anomalous origin and course of the right coronary artery. Circulation 114(22):e609-e611

McCarthy M (1999) Study identifies heart surgery patients at risk for stroke. Lancet 354:354-575

Mellin-Olsen J, Staender S, Whitaker DK, Smith AF (2010) The Helsinki declaration on patient safety in anesthesiology. Eur J Anaesthesiol 27:592-597

Moar JJ (1996) South African Anaesthetic-associated mortality and anaesthetic contributory death: the South African medicolegal approach. Forensic Sci Int 78:219-230

Morray JP, Geiduscheck JM, Ramamoorthy C et al (2000) Anesthesia-related cardiac arrest in children: initial findings of the Pediatric Perioperative Cardiac Arrest (POCA) registry. Anesthesiology 93:6-14

Nanji KC, Patel A, Shaikh S, Seger DL, Bates DW (2016) Evaluation of perioperative medication errors and adverse drug events. Anesthesiology 124(1):25-34

Neelakanta G, Chikyarappa A (2006) A review of patients with pulmonary aspiration of gastric contents during anesthesia reported to the departmental quality assurance committee. J Clin Anesth 18:102-107

Newland MC, Ellis SJ, Lydiatt CA, Peters KR, Tinker JH, Romberg DJ, Ullrich FA Anderson JR (2002) Anesthetic-related cardiac arrest and its mortality: a report covering 72,959 anesthetics over 10 years from a US teaching hospital. Anesthesiology 97:108-115

O'Grady G (2003) Death of the teaching autopsy. BMJ 327:802-803

Paix AD, Williamson JA, Runciman WB (2005) Crisis management during anaesthesia: difficult intubation. Qual Saf Health Care 14:156-163

Patil H, Garg N, Banabokade L, Navakar D (2019) Lumbar spine surgeries under spinal anesthesia in high risk patients: a retrospective analysis. World Neurosurg 124:e779

Payne V, Kam PCA (2004) Mast cell tryptase: a review of its physiology and clinical significance. Anaest 59(7):695-703

Pitkänen MT, Aromaa U, Cozanitis DA, Förster JG (2013) Serious complications associated with spinal and epidural anaesthesia in Finland from 2000 to 2009. Acta Anaesthesiol Scand 57(5):553-564

Pitt-Miller P (1989) Deaths within 24 hours of surgical procedures at the Port-ofSpain General Hospital. West Indian Med J 38:148-152

Pollard JB (2001) Cardiac arrest during spinal anesthesia: common mechanims and strategies for prevention. Anesth Anal 92(1):252-6

Preckel B, Bolten J (2005) Pharmacology of modern volatile anaesthetics. Best Pract Res Clin Anaesthesiol 19:331-348

Procaccianti P, Farè F, Argo A, Casagni E, Arnoldi S, Facheris S, Visconti GL, Roda G, Gambaro V (2017) Determination of Propofol by GC/MS and fast GC/MS-TOF in two cases of poisoning. J Anal Toxicol 41:771-776

Rancati A, Andreola S, Bailo P, Boracchi M, Fociani P, Gentile G, Zoja R (2018) Lethal cardiac amyloidosis: modification of the Congo red technique on a forensic case. Forensic Sci Int 289:150-153

Randall B, Butts J, Halsey JF (1995) Elevated postmortem tryptase in the absence of anaphylaxis. J Forensic Sci 40:208-211

Rashid AMH, Williams RM (1994) Sudden death caused by giant cell myocarditis following coronary artery bypass. Am J Forensic Med and Pathol 15:82-86

Rini MS, Argo A, Spagnolo EV, Zerbo S, Bucci MB, D'Urso D (2018) When is necessary not to apply guidelines? Pitfalls in dentistry practice. Dent Cadmos 86(8):686-695

Roberts ISD, Pumphrey RSH (2001) The autopsy in fatal anaphylaxis. Rec Adv Pathol 19:145-162

Rosenberg M, Weaver J (1991) General anesthesia. Anesth Prog 38:172-186

Saukko P, Knight B (2016) Death associated with surgical procedure. In: Saukko P, Knight B (eds) Knight's forensic pathology, 4ht edn. CRC Press Taylor \& Francis Group, Boca Raton, pp 497-507

Serretta V, Abrate A, Siracusano S, Gesolfo CS, Vella M, Di Maida F, Cangemi A, Cicero G, Barresi E, Sanfilippo C (2018) Clinical and biochemical markers of visceral adipose tissue activity: body mass index, visceral adiposity index, 
leptin, adiponectin, and matrix metalloproteinase-3. Correlation with Gleason patterns 4 and 5 at prostate biopsy. Urol Ann 10:280-286

Sheppard HN, Anandampillai R (2019) Systemic toxic effects of local anaesthetics. Anaesth Intensive Care Med 4(20):215-218

Solazzi RW, Ward RJ (1984) The spectrum of medical liability cases. Int Anesth Clinics 22:43-59

Stefani LC, Gamermann PW, Backof A et al (2018) Perioperative mortality related to anestesia within $48 \mathrm{~h}$ and up to 30 days following surgery: a retrospective cohort study of 11,562 anesthetic procedures. J Clin Anesth 49:79-86

Tanne JH (1998) Food and drugs alter response to anesthesia. BMJ 317:1 102

Tikkanen J, Hovi-Viander M (1995) Death associated with anaesthesia and surgery in Finland in 1986 compared to 1975. Acta Anaesthesiol Scand 39:262-267

Tiret L, Desmonts JM, Hatton F, Vourch G (1986) Complications associated with anaesthesia - a prospective survey in France. Can Anaesth Soc J 33:336-344

Tourtier JP, Compain M, Petitjeans F et al (2004) Acid aspiration prophylaxis in obstetrics in France: a comparative survey of 1998 versus 1988 French practice. Eur J Anaesthesiol 21:89-94

Van der Walt JH, Webb RK, Osborne GA, Morgan C, Mackay P (1993) The Australian Incident Monitoring Study. Recovery room incidents in the first 2000 incident reports. Anaesth Intensive Care 21:650-652

Vassalo SA (1997) The first death associated with anesthesia. Anesthesiology 87:928 Venturini M, Lobera T, Del Pozzo MD et al (2006) Immediate hypersensitivity to corticosteroids. J Investig Allergol Clin Immunol 16:51-56

Warner MA, Warner ME, Weber JG (1993) Clinical significance of pulmonary aspiration during the perioperative period. Anesthesiology 78:56-62

\section{Submit your manuscript to a SpringerOpen ${ }^{\circ}$ journal and benefit from:}

- Convenient online submission

- Rigorous peer review

- Open access: articles freely available online

High visibility within the field

- Retaining the copyright to your article

Submit your next manuscript at $\boldsymbol{\nabla}$ springeropen.com 